\title{
Inflammatory and endothelial markers during the menstrual cycle
}

Roza Chaireti, Tomas Lindahl, Birgitta Bystrom, Katarina Bremme and Anders Larsson

\author{
Journal Article
}

\section{Tweet}

N.B.: When citing this work, cite the original article.

This is an electronic version of an article published in:

Roza Chaireti, Tomas Lindahl, Birgitta Bystrom, Katarina Bremme and Anders Larsson, Inflammatory and endothelial markers during the menstrual cycle, Scandinavian Journal of Clinical and Laboratory Investigation, 2016. 76(3), pp.190-194.

Scandinavian Journal of Clinical and Laboratory Investigation is available online at informaworldTM:

http://dx.doi.org/10.3109/00365513.2015.1129670

Copyright: Taylor \& Francis: STM, Behavioural Science and Public Health Titles http://www.tandf.co.uk/journals/default.asp

Postprint available at: Linköping University Electronic Press

http://urn.kb.se/resolve?urn=urn:nbn:se:liu:diva-127556

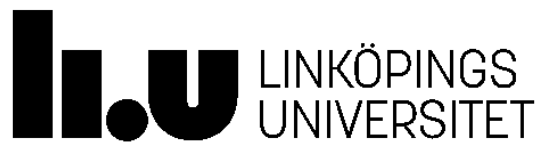


Inflammatory and endothelial markers during the menstrual cycle.

Running head: inflammation during the menstrual cycle

Roza Chaireti ${ }^{*}$, Tomas L. Lindahl ${ }^{2}$, Birgitta Byström ${ }^{3}$, Katarina Bremme ${ }^{3}$ and Anders

$\operatorname{Larsson}^{4}$

${ }^{1}$ Department of Molecular Medicine and Surgery, Karolinska Institutet, 171 76, Stockholm,

Sweden

${ }^{2}$ Department of Clinical and Experimental Medicine, Linköping University, 58183 ,

Linköping, Sweden

${ }^{3}$ Department of Women's and Children's Health, Division of Obstetrics and Gynecology, Karolinska Institutet, 171 76, Stockholm, Sweden

${ }^{4}$ Department of Medical Sciences, Uppsala University, 751 05, Uppsala, Sweden

Corresponding author:

Roza Chaireti

Department of Molecular Medicine and Surgery

Karolinska Institutet

Stockholm 17176

Sweden

telephone number: +46851770000

e-mail: roza.chaireti@ki.se 


\begin{abstract}
Background: The menstrual cycle exhibits a pattern of repeated inflammatory activity. The present study aims to evaluate inflammatory and endothelial markers during the two phases of a menstrual cycle.
\end{abstract}

Methods: The study cohort consisted of 102 women with regular menstrual cycles. Inflammatory and endothelial markers (interleukin-6 [IL-6], pentraxin-3, hs-C reactive protein [hs-CRP], sE-selectin, sP-selectin, intracellular and vascular cell adhesion molecules [ICAM-1 and VCAM-1] and cathepsins L, B and K) were measured during the early follicular and the late luteal phase of a normal menstrual cycle.

Results: PTX-3 and hs-CRP were significantly higher during the follicular phase compared to the luteal phase $(p<0.001$ respectively $p=0.025)$. The other inflammatory and endothelial markers, with the exception of cathepsin B, were higher, albeit not significantly, during the follicular phase.

Conclusions: Inflammatory activity, expressed mainly by members of the pentraxin family, is higher during the early follicular compared to the luteal phase. This could be associated to menstruation but the exact mechanisms behind this pattern are unclear and might involve the ovarian hormones or an effect on hepatocytes.

Keywords: inflammation, menstrual cycle, pentraxin 


\section{Introduction}

The female reproductive system, including ovulation and menstruation, shares molecular and cellular mediators with the inflammatory system [1]. The endometrium in particular, is an example of cyclic inflammatory activity [2]. The studies on the variations of inflammatory markers during the course of a menstrual cycle are few and have been performed in small cohorts and the data is somewhat limited.

C-reactive protein (CRP) is an acute phase protein produced by the liver in response to inflammation [3]. During the course of a menstrual cycle, the highest levels of CRP have been reported during the early follicular phase [4]. Pentraxin-3 is a member of the pentraxin superfamily and has a dual role in inate immunity and female fertility, especially in carriers of specific single-nucleotide polymorphisms (SNPs) [5]

The intercellular adhesion molecule 1 (ICAM-1) and vascular cell adhesion molecule 1 (VCAM-1) are involved in leukocyte trafficking and inflammation [6, 7]. Both ICAM-1 and VCAM-1 are expressed in the human ovary and have been shown to vary during the menstrual cycle [8], reaching their peak during ovulation.

Cathepsins are lysosomal cysteine proteinases that participate in a variety of proteolytic processes. Cathepsins B, L and S are present in the endometrium during both phases of the menstrual cycle and it has been suggested that they are necessary for its development and normal function [9]. 
The aim of this study was to investigate the changes in selected inflammatory and endothelial markers during a regular menstrual cycle. We chose inflammatory and endothelial markers that have been shown to vary during the menstrual cycle or are associated to hormonal changes. The results were correlated to levels of estradiol, progesterone, anti-müllerian hormone $(\mathrm{AMH})$ and sex hormone binding globulin (SHBG) measured at the same time points.

\section{Study participants and methods}

\section{Study participants}

The study cohort consisted of 104 healthy premenopausal women not taking any form of hormone medications. Inclusion criterion was a history of regular menstrual cycles and exclusion criteria were pregnancy, hormonal therapy or breast-feeding within 2 months prior to the start of the study. Two women were excluded ( 1 due to severe problems with the blood sampling and 1 withdrew consent due to personal reasons). Subsequently, the results below refer to 102 women (table I).

Fifty-three women (52\%) were nulligravidae, 12 (11\%) had one pregnancy, $16(16 \%)$ two pregnancies, $7(7 \%)$ three pregnancies, $6(6 \%)$ four pregnancies, $5(5 \%)$ five pregnancies, 2 (2\%) six pregnancies and $1(1 \%)$ eight pregnancies. Of the $49(48 \%)$ women who had been pregnant at least once, $8(16.5 \%)$ had delivered no children, 11 women $(22.5 \%)$ had delivered one child, 19 (39\%) two children, 7 (14\%) three children and 4 (8\%) women four children each. Nine women $(9 \%)$ had at least one miscarriage. 
For the characteristics of the women included in the study, see table I.

\section{Ethical approval}

Written consent was obtained from all participants prior to inclusion in the study and the study protocol was approved by the local Ethics Committee.

\section{Blood sampling and handling}

Blood samples were collected during the early follicular (cycle day, cd 3-5) and late luteal (cd 22-25) phase of the menstrual cycle from each volunteer. Venous blood samples were drawn from an antecubital vein after $15 \mathrm{~min}$ in the supine position, collected in tubes containing 0.13 mM citrate (Vacutainer, Becton Dickinson, Meylen, France) and immediately centrifuged at $2000 \mathrm{~g}$ for $15 \mathrm{~min}$. After removal of the cells, plasma was re-centrifuged for another $15 \mathrm{~min}$ at 2000g. Blood for serum preparation was collected in plain Vacutainer tubes without anticoagulants and kept at room temperature for $1 \mathrm{~h}$ before centrifugation at $2000 \mathrm{~g}$ for $10 \mathrm{~min}$. Cell-free plasma and serum samples were stored at $-70^{\circ} \mathrm{C}$ until analysed.

\section{Measurement of inflammatory and endothelial markers}

Interleukin-6 (IL-6) was measured by an ELISA method (Quantikine) using human IL-6 (R\&D Systems, Abingdon, UK). Pentraxin-3 (PTX-3) (DY1826), sE-selectin (DY724), sPselectin (DY137), ICAM-1 (DY720), VCAM-1 (DY809), cathepsin L (DY952), cathepsin B (DY2176) and cathepsin S (DY1183) were analysed by ELISAs from R\&D Systems.

High sensitivity-C reactive protein (CRP) was measured on an Architect Ci8200 analyser (Abbott Laboratories, Abbott Park, IL, USA). 


\section{Measurement of hormones and SHBG}

Serum concentrations of progesterone and SHBG were determined by the direct chemiluminescence enzyme immunoassays Imulite 1000 using commercial kits from Diagnostic Products Corporation, Los Angeles, CA. Estradiol levels were analysed by a sensitive Spectria radioimmunoassay from Orion Diagnostica (Espoo, Finland). AMH was determined by ELISA using a commercial kit (AMH Gen II ELISA; Beckman Coulter).

\section{Statistical analysis}

All the results were analysed using the program SPSS, Systat Inc Software. As the number of observations (n) was greater than 30 , we used the paired t-test (statistical significance when $\mathrm{p}<0.05$, CI $95 \%$ ) in order to determine the differences in the levels of inflammatory and endothelial markers in the luteal and follicular phase for each volunteer.

The correlations between hormones, SHBG and inflammatory and endothelial markers were evaluated by simple correlation method for continuous data (Pearson's), according to the Dancey and Reidy's categorisation ( $\mathrm{r}=0.1-0.3$ weak correlation, 0.4-0.6 moderate correlation, 0.7-0.9 strong correlation) [10].

\section{Results}

All values reported below are expressed as mean \pm SD.

Inflammatory and endothelial markers during the follicular and luteal phase of the menstrual cycle and their correlations to hormones and SHBG 
PTX-3 and hs-CRP were significantly higher during the follicular phase compared to the luteal phase (PTX-3: $\mathrm{p}<0.001,2152 \mathrm{pg} / \mathrm{ml}$ vs. $1752 \mathrm{pg} / \mathrm{ml}$ and hsCRP: $\mathrm{p}=0.025,1.65 \mathrm{mg} / \mathrm{l} \mathrm{vs}$. $0.89 \mathrm{mg} / \mathrm{l})$. No statistically significant differences were observed for the other markers; however, all markers but cathepsin $\mathrm{B}$ and sP-selectin were higher during the follicular phase (table II).

No significant correlations were observed between the inflammatory and endothelial markers, the hormones measured (progesterone, estradiol, AMH) and SHBG.

\section{Discussion}

The pattern that emerged showed that the inflammatory response is more pronounced during the early follicular phase compared to the luteal phase, even though those differences did not always reach statistical significance. This is the first time, to our knowledge, that different types of inflammatory and endothelial markers are studied together in this context and are shown to have a similar pattern.

Bonello and Norman showed that ICAM-1 reaches its peak in the early and mid-follicular phase and that both ICAM-1 and VCAM-1 decrease during the rest of the cycle [8]. In our study, however, although both proteins were higher during the early follicular phase, the differences did not reach statistical significance. The number of subjects in [8] was lower $(n=10)$ than in our study and the blood sampling took place at 8 time-points during one cycle, thus highlighting even subtler differences.

The variations of the adhesion molecules sP-selectin and sE-selectin during the menstrual 
cycle have been studied before in smaller cohorts with varying results $[8,11-14]$. In our study, P-selectin was slightly, but not significantly, higher during the luteal phase, which is in contrast with previous findings $[11,14]$, however the cohorts in both studies were smaller and the timing for the blood sampling different. E-selectin was practically unchanged during the menstrual cycle, as observed previously [8]. It has been previously reported that e-selectin decreases following menopause [15] whereas it increases during hormonal treatment (combined oral contraceptives, COC and hormone replacement therapy) [16]. A clear association with hormonal changes is thus shown, although the more discreet changes during a menstrual cycle do not appear to induce such variations.

In accordance with previous studies [17, 18], IL-6 was higher during the follicular phase, but this difference did not reach statistical difference. In contrast to [17], however, no correlation was found between IL-6 and estradiol. The cohort in [17] was smaller than ours, which could lead to discrepancies in the results due to differences in the statistical power.

The relations between female sex hormones and CRP depend on whether the hormones are endogenous or administered (exogenous). Endogenous estrogen has been associated with decreases in CRP whereas exogenous estrogen, especially when administered orally [16] has the opposite effect. Similarly, despite the fact that exogenous progesterone seems to be associated with decreases in CRP, it appears that endogenous progesterone is associated with increases in CRP [19]. This would place the higher CRP concentration at some point during the beginning of the follicular phase [4], as shown in our study. However, no associations between hs-CRP and hormones were observed. 
Both PTX-3 and CRP belong to the protein superfamily of pentraxins and are synthesized under the guidance of interleukins, most prominently IL-6 [20]. CRP is mainly produced in the liver while PTX-3 is produced locally in the inflamed tissue. The differences in synthesis sites and the fact that PTX-3 has previously been reported to be an early marker for preeclampsia and endothelial dysfunction $[20,21]$ was the reason for including PTX-3 in this study. However, we found no clear differences between CRP and PTX-3. This study showed that both PTX-3 and CRP were significantly higher during the follicular phase, whereas IL-6 was only marginally higher. It is known that CRP is higher during the menstruation [19] and that is confirmed by our results, too (as the early follicular phase in the ovarian cycle corresponds to the menstruation in the uterine cycle when this nomenclature is used). It has also been hypothesized that higher CRP during the follicular phase is a marker of greater ovarian reserve, as it has been associated with higher number of follicular waves [22] and greater number of antral follicles [23]. PTX-3 is under strict hormonal control and is upregulated during ovulation; it has also been shown to play a role in female fertility [24]. It would appear that members of the pentraxin superfamily are largely responsible for the inflammatory activity during the early follicular phase and are additionally associated to markers with dual inflammatory and coagulation activity.

In a previous study on the same cohort [25], a cycle was considered ovulatory if: i) the progesterone level in the luteal phase was above $15 \mathrm{nM} / \mathrm{L}$ and increased compared with the follicular phase level and ii) the estradiol level was increased in the follicular compared to the luteal phase. Of the 102 women included in the study, 16 were assessed as having anovulatory cycles at the time of the sampling. In addition, as 14 women had hormone levels that did not fulfil either criterion (i) or (ii), it could not be concluded whether they should be classified as having anovulatory or ovulatory cycles. The presence of ovulation in the women included in 
the study was therefore not assessed by objective methods [26, 27, 28]. All the statistical analyses were repeated excluding the 16 women who were assessed as having anovulatory cycles and the results were not affected (data not shown). Thus, the final report includes all women, regardless of ovulation.

The main strength of the study is its large cohort, which adds to the reliability of the results as most previous studies in the field have been performed in smaller cohorts. The main weakness of the study is that we could not provide the mechanisms behind our observations Lack of available material has restricted the amount of analyses we were able to perform.

In conclusion, this study contributes to the current knowledge on inflammatory response during the menstrual cycle. We showed that a variety of vascular and inflammatory markers are increased in different grades during the early follicular phase (corresponding to menstruation). Increased CRP concentration during treatment with COCs has been associated with a direct effect on hepatocytes, and not with IL-6 mediated inflammation [16]. This effect was not studied in our report, and could thus be part of the explanation. Larger studies including also the inflammatory markers with known associations to ovarian hormones could be useful tools to investigate this hypothesis. 


\section{Acknowledgments}

The authors are grateful to biotechnologist Kerstin M. Gustafsson for excellent laboratory assistance.

\section{Tables}

\begin{tabular}{|c|c|c|c|c|c|}
\hline $\begin{array}{l}\text { Cohort } \\
\text { (n) }\end{array}$ & $\begin{array}{l}\text { Age } \\
(\text { mean } \pm \text { SD) }\end{array}$ & $\begin{array}{l}\text { BMI } \\
(\text { mean } \pm \text { SD })\end{array}$ & $\begin{array}{l}\text { Number of } \\
\text { pregnancies } \\
0 / 1 / 2 / 3 / 4 / 5 / 6 / 8\end{array}$ & $\begin{array}{l}\text { Number of } \\
\text { deliveries } \\
0 / 1 / 2 / 3 / 4\end{array}$ & $\begin{array}{l}\text { Anovulatory } \\
\text { cycle (n) }\end{array}$ \\
\hline 102 & $31.7 \pm 8.6$ & $23 \pm 3$ & $53 / 12 / 16 / 7 / 6 / 5 / 1$ & $8 / 11 / 19 / 7 / 4$ & 16 \\
\hline
\end{tabular}

Table I. Characteristics of the participants in the study.

\begin{tabular}{|l|l|l|l|}
\cline { 2 - 4 } \multicolumn{1}{l|}{} & Follicular phase & Luteal phase & $\mathrm{p}$ \\
\hline PTX-3 $(\mathrm{pg} / \mathrm{ml})$ & $2152 \pm 911$ & $1752 \pm 835$ & $<0.001$ \\
\hline hs-CRP $(\mathrm{mg} / \mathrm{l})$ & $1.65 \pm 3$ & $0.89 \pm 1$ & 0.025 \\
\hline IL-6 $(\mathrm{pg} / \mathrm{ml})$ & $1.03 \pm 1$ & $0.77 \pm 1$ & 0.151 \\
\hline sP-selectin $(\mathrm{pg} / \mathrm{ml})$ & $107786 \pm 66780$ & $108846 \pm 59792$ & 0.554 \\
\hline sE-selectin $(\mathrm{pg} / \mathrm{ml})$ & $25571 \pm 9070$ & $25179 \pm 8606$ & 0.849 \\
\hline VCAM-1 $(\mathrm{pg} / \mathrm{ml})$ & $370390 \pm 87165$ & $359360 \pm 75901$ & 0.168 \\
\hline ICAM-1 $(\mathrm{pg} / \mathrm{ml})$ & $136515 \pm 32654$ & $132175 \pm 31001$ & 0.215 \\
\hline CATHL $(\mathrm{pg} / \mathrm{ml})$ & $6399 \pm 3289$ & $6185 \pm 2908$ & 0.725 \\
\hline CATHB $(\mathrm{pg} / \mathrm{ml})$ & $37326 \pm 15093$ & $38843 \pm 16157$ & 0.198 \\
\hline CATHS (pg/ml) & $11700 \pm 2732$ & $11542 \pm 2787$ & 0.937 \\
\hline
\end{tabular}


Table II. Values of inflammatory and vascular markers during the follicular and luteal phase of the menstrual cycle. The values are expressed as mean $\pm \mathrm{SD}$.

\section{References}

[1] Brännström M, Norman RJ. Involvement of leukocytes and cytokines in the ovulatory process and corpus luteum function. Hum Reprod 1993;8:1762-75.

[2] Maybin JA, Critchley HOD. Progesterone: a pivotal hormone at menstruation. Ann NY Acad Sci 2011;1221:88-97.

[3] Thompson D, Pepys MB, Wood SP.The physiological structure of human C-reactive protein and its complex with phosphocholine. Structure 1999;7:169-77.

[4] Baerwald AR, Adams GP, Pierson RA. Form and function of the corpus luteum during the human menstrual cycle. Ultrasound Obstet Gynecol 2005;25:498-507.

[5] May L, Kuningas M, van Bodegom D, Meij HJ, Frolich M, Slagboom PE, Mantovani A, Westendorp RGJ. Genetic Variation in Pentraxin (PTX) 3 Gene Associates with PTX3 Production and Fertility in Women. Biol Reprod 2010;82:299-304.

[6] Minami T, Sugiyama A, Wu SQ, Abid R, Kodama T, Aird WC. Thrombin and phenotypic modulation of the endothelium. Arterioscler Thromb Vasc Biol 2004;24:41-53.

[7] Kaplanski G, Marin V, Fabrigoule M, Boulay V, Benoliel AM, Bongrand P, Kaplanski S, Farnarier C. Thrombin-activated human endothelial cells support monocyte adhesion in vitro following expression of intercellular adhesion molecule-1 (ICAM- 1; CD54) and vascular cell adhesion molecule-1 (VCAM-1; CD106). Blood 1998;92:1259-67.

[8] Bonello N, Norman RJ. Soluble adhesion molecules in serum throughout the menstrual cycle. Hum Reprod 2002;17:2272-8.

[9] Jokimaa V, Oksjoki S, Kujari H, Vuorio E, Anttila L. Expression patterns of cathepsins B, H, K, L and S in the human endometrium. Mol Hum Reprod 2001;7:73-8. 
[10] Dancey C, Reidy J. Statistics without Maths for Psychology: using SPSS for Windows. Prentice Hall, London, UK 2004.

[11] Jilma B, Hildebrandt J, Kapiotis S, Wagner OF, Kitzweger E, Müllner C, Monitzer B, Krejcy K, Eichler HG. Effects of estradiol on circulating SP-selectin. J Clin Endocrinol Metabol 1996;81:2350-5.

[12] Elhadd TA, Neary R, Abdu TA, Kennedy G, Hill A, McLaren M, Akber M, Belch JJ, Clayton RN. Influence of the hormonal changes during the normal menstrual cycle in healthy young women on soluble adhesion molecules, plasma homocysteine, free radical markers and lipoprotein fractions. Int Angiol 2003;22:222-8.

[13] Robb AO, Din JN, Mills NL, Smith IB, Blomber A, Zikry MN, Raftis JB, Newby DE, Denison FC. The influence of the menstrual cycle, normal pregnancy and pre-eclampsia on platelet activation. Thromb Haemost 2010;103:372-8.

[14] Rosin C, Brunner M, Lehr S, Quehenberger P, Panzer S. The formation of plateletleukocyte aggregates varies during the menstrual cycle. Platelets 2006;17:61-6.

[15] Vehkavaara S, Silveira A, Hakala-Ala-Pietilä T, Virkamäki A, Hovatta O, Hamsten A, Taskinen MR, Yki-Järvinen H. Effects of oral and transdermal estrogen replacement therapy on markers of coagulation, fibrinolysis, inflammation and serum lipids and lipoproteins in postmenopausal women. Thromb Haemost 2001;85:619-25.

[16] Van Rooijen M, Hansson LO, Frostegård J, Silveira A, Hamsten A, Bremme K.

Treatment with combined oral contraceptives induces a rise in serum C-reactive protein in the absence of a general inflammatory response. J Thromb Haemost 2006;4:77-82.

[17] Chiu KM, Arnaud CD, Ju J, Mayes D, Bacchetti P, Weits S, Keller ET. Correlation of estradiol, parathyroid hormone, interleukin-6, and soluble interleukin-6 receptor during the normal menstrual cycle. Bone 2000;26:79-85. 
[18] Angstwurm MW, Gärtner R. Ziegler-Heitbrock HW. Cyclic plasma IL-6 levels during normal menstrual cycle. Cytokine 1997;9:370-4.

[19] Wander K, Brindle E, O’Connor KA. C-reactive protein across the menstrual cycle. Am J Phys Anthropol 2008;136:138-46.

[20] Kunes P, Holubcova Z, Kolackova M, Krejsek J. Pentraxin 3 (PTX 3): an endogenous modulator of the inflammatory response. Mediators Inflamm 2012;2012:920517.

[21] Hamad RR, Eriksson MJ, Berg E, Larsson A, Bremme K. Impaired endothelial function and elevated levels of pentraxin 3 in early-onset preeclampsia. Acta Obstet Gynecol Scand 2012;91:50-6.

[22] Clancy KBH, Baerwald AR, Pierson RA. Systemic inflammation is associated with ovarian follicular dynamics during the human menstrual cycle. PLoS ONE 2013;8:e64807. [23] Vanden Brink H, Robertson D, Hale G, Chizen D, Baerwald A. Antral ovarian follicular dynamics during reproductive aging in women (abstract). Proceedings of the STRAW +10 Symposium: Addressing the Unfinished Agenda of Staging Reproductive Aging. Menopause $2011 ; 18: 1377-8$

[24] May L, Kuningas M, van Bodegom D, Meij HJ, Frolich M, Slagboom PE, Mantovani A, Westendorp RG. Genetic variation in pentraxin (PTX) 3 gene associates with PTX3 production and fertility in women. Biol Reprodn 2010;82:299-304.

[25] van Rooijen M, Silveira A, Thomassen S, Odeberg J, Hamsten A, Rosing J, Bremme K. APC resistance during the normal menstrual cycle. Thromb Haemost 2007;98:1246-51. [26] Jinno M, Ozaki T, Iwashita M, Nakamura Y, Kudo A, Hirano H. Measurement of endometrial tissue blood flow: a novel way to assess uterine receptivity for implantation. Fertil Steril 2001;76:1168-74.

[27] Zec I, Tislarić-Medenjak D, Bukivec-Megla Z, Harni V, Kusić Z. Serum levels of antimüllerian hormone in women with regular menstrual cycles. Acta Clin Croat 
2010;49:405-9.

[28] Mihm M, Gangooly S, Muttukrishna S. The normal menstrual cycle in women. Ani Reprod Sci 2011;124:229-36. 